\title{
A Complementary Bipolar Technology Family With a Vertically Integrated PNP for High-Frequency Analog Applications
}

\author{
Rashid Bashir, François Hébert, Joseph DeSantis, Joel M. McGregor, Wipawan Yindeepol, Kevin Brown, \\ Farhood Moraveji, Thomas B. Mills, Alexei Sadovnikov, James McGinty, Member, IEEE, Peter Hopper, \\ Robert Sabsowitz, Mohamed Khidr, Tracey Krakowski, Linda Smith, and Reda Razouk
}

\begin{abstract}
Silicon complementary bipolar processes offer the possibility of realizing high-performance circuits for a variety of analog applications. This paper presents a summary of silicon complementary bipolar process technology reported in recent years. Specifically, an overview of a family of silicon complementary bipolar process technologies, called Vertically Integrated PNP (VIP ${ }^{\text {TM1 }}$ ), which have been used for the realization of high-frequency analog circuits is presented. Three process technologies, termed VIP-3, VIP-3H, and VIP-4H offer device breakdowns of 40, 85, and $170 \mathrm{~V}$, respectively. These processes feature optimized vertically integrated bipolar junction transistors (PNPs) along with high performance NPN transistors with polycrystalline silicon emitters, low parasitic polycrystalline silicon resistors, and metal-insulator-polycrystalline silicon capacitors. Key issues and aspects of the processes are described. These issues include the polycrystalline silicon emitter optimization and vertical and lateral device isolation in the transistors. Circuit design examples are also described which have been implemented in these technologies.
\end{abstract}

\section{INTRODUCTION}

A NALOG circuits are an integral part of any electronic system in use today and will find increasing use in applications where high voltages or an interface to the outside world is required. With the increasing demands of higher performance, high speed, and low distortion operational amplifiers, circuit designers need higher performance complementary bipolar technologies specifically aimed for analog applications. Even though the complementary bipolar process technology drives a smaller part of the market than core high-density complementary metal-oxide semiconductor (CMOS) technology,

Manuscript received July 2, 1999; revised August 1, 2000. The review of this paper was arranged by Editors P. Asbeck and T. Nakamura.

R. Bashir is with the School of Electrical and Computer Engineering, Purdue University, West Lafayette, IN 47907 USA.

F. Hébert is with the Linear Technology Corporation, San Jose, CA 95101 USA.

J. DeSantis, W. Yindeepol, T. B. Mills, A. Sadovnikov, J. McGinty, P. Hopper R. Sabsowitz, M. Khidr, T. Krakowski, L. Smith, and R. Razouk are with the Advanced Process Technology Group, National Semiconductor, Santa Clara, CA 95050 USA.

J. M. McGregor is with Maxim Integrated Products, Sunnyvale, CA 94085 USA.

K. Brown and F. Moraveji are with Micrel, Milpitas, CA 95035 USA.

Publisher Item Identifier S 0018-9383(01)09064-5. CA. it still constitutes a very important segment of the overall integrated circuit market. Specifically, a high-performance bipolar junction transistor (PNP) is very desirable in the signal path because it can offer the opportunity for designing push-pull circuits and active loads for analog applications. In addition, high performance PNPs can enhance the circuit performance as drivers in the output stages by reducing the supply current. The key requirements for analog process technology are the required breakdown voltages for specific applications, high $\beta x V a$ product, high $f_{T}$ and $f_{\max }$ for high speed applications, and low noise for both NPN and PNP devices. Other important requirements for the success for any technology are, of course, low cost and manufacturability.

Unlike MOS process technology, bipolar process technology is typically not truly complementary. In most cases, only vertical NPN bipolar junction transistors are optimized and PNP bipolar junction transistors are usually "free," i.e., no added processes steps are needed. The two main types of these "free" PNP devices are i) substrate PNP and ii) Lateral PNP. Substrate PNPs are made from the NPN p-type base, n-type collector, and p-type substrates. Hence these devices are not isolated from each other and are connected through the substrate. The lateral PNP devices are made using the p-type extrinsic base, n-type collector, and the p-type extrinsic base of the NPN. The base contact is provided by the NPN n+ buried layer. The word "lateral" refers to the direction of the current flow with respect to the wafer surface since in these devices the current flows laterally from the emitter to the collector, unlike in vertical devices where the current flows from the emitter down to the collector and the buried layer. The lateral device has a large base resistance and hence a poor $f_{T}$ and $f_{\max }$, limiting its use in high frequency applications. Thus, both these types of devices are not suited for high frequency, switching, or high performance applications. Fig. 1 shows the three types of PNP devices possible in a NPN process.

The purpose of this paper is to discuss silicon complementary bipolar technologies and their applications. The complementary bipolar processes reported to date in literature are also summarized. In addition, a family of processes called VIPTM is described. Three processes with device breakdowns at 40, 85, and $170 \mathrm{~V}$ are described. Key process issues are described and circuit design examples are presented that utilize the unique features of these technologies. 


\section{Lateral PNP}

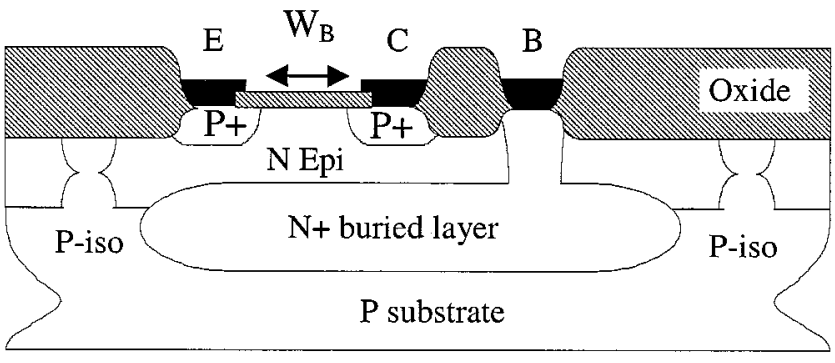

(a)

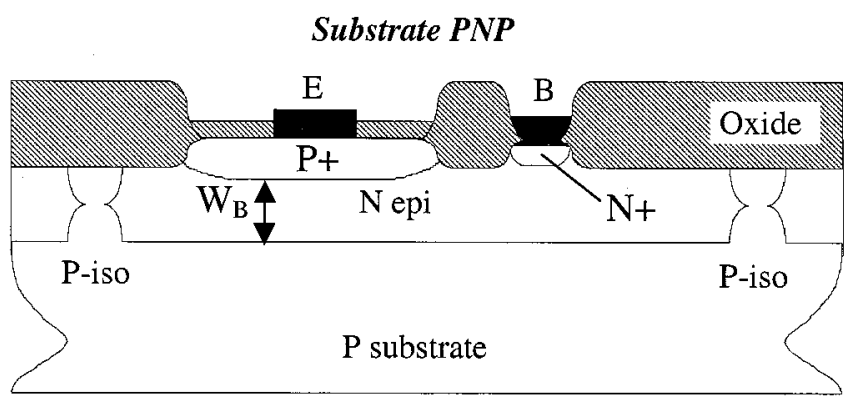

(b)

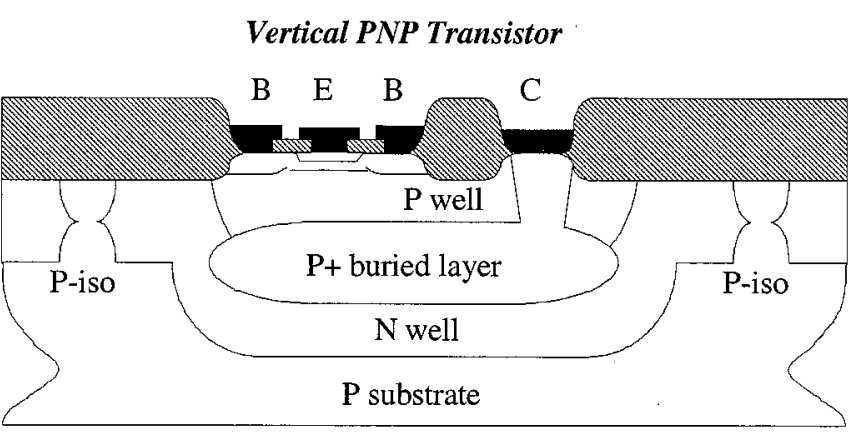

(c)

Fig. 1. The three types of PNP devices typically used in NPN BJT processes: (a) lateral PNP, (b) substrate PNP, and (c) vertical PNP.

\section{REVIEW OF COMPLEMENTARY BIPOLAR TECHNOLOGIES}

Many complementary bipolar technologies are reported in the literature from the late 1960 s to very recently [1]-[38]. From its early inception, complementary bipolar processes have been used for realizing high performance analog circuits. In one of the earliest reports of the complementary bipolar technologies in 1968 [1], NPN and PNP devices were achieved in a monolithic structure by fabricating them in different wafers and then soldering the two wafers together face to face. The wafers were aligned within an accuracy of $1 \mathrm{mil}(25 \mu \mathrm{m})$ by fitting metal bumps on one wafer into pockets on the other wafer. Subsequently, the two types of devices were fabricated within the single substrate for the first time [2]. This opened the way for integrated complementary bipolar device. Su et al. [3] used one extra diffusion to devise NPN and PNP devices with high current gain and low saturation resistance. Many authors subsequently reported integration of PNP devices and their optimization in NPN process, thus realizing complementary bipolar processes [4]-[9].

Since the early 1980 s, there have been many reports of high performance complementary bipolar processes for analog applications. One of the first high voltage processes was described by Aull, et al. [10] with breakdown voltages of $60 \mathrm{~V}$ for telecom subscriber line interface circuits. The process produced vertical NPN and PNP devices with $B V$ ceo of $60 \mathrm{~V}$ and $\beta$ of about 100 . Subsequently, a circuit for a line interface between two-wire subscriber loops and the low-voltage four-side of a telephone exchange was described using a complementary $(C)$-bipolar technology [11]. Low voltage and digital functions were provided in standard $60 \mathrm{~V}$ junction isolated process. The high voltage two-wire side of the subscriber circuit was built in a $200 \mathrm{~V}$ dielectrically isolated complementary bipolar technology. A process was also reported with vertically double diffused transistors in complementary islands with breakdown voltages of more than $350 \mathrm{~V}$ and $\mathrm{f}_{\mathrm{T}}$ of 450 and $200 \mathrm{MHz}$ for the NPN and PNP transistors, respectively [12]. A subscriber line interface circuit that includes battery feed, supervision, and hybrid was demonstrated using this technology. An ion-implanted base-emitter in a complementary bipolar process was reported with reduction in leakage currents from ion-implanted boron for the PNP emitter [13], [14]. In order to reduce parasitics, various authors have reported devices fabricated on silicon-on-insulator (SOI) wafers and trench isolation. Bonded and etched back SOI (BESOI) wafers have found significant use in these processes [15], [18]-[21], [26], [35]-[37]. SOI wafers make the process simpler, i.e., no n-wells are needed for the PNP device isolation, and the device size and parasitic capacitances are reduced. The use of trenches and SOI does increase the wafer cost and hence many junction isolated processes made in bulk wafers have also been reported [17], [23], [29], [30], [32], [34], [38].

\section{VIPTM PROCESS DETAILS}

In order to fulfill the need for high-precision and high-frequency analog circuits, a family of complementary silicon bipolar processes has been developed [29], [30], [35], [36]. Three technologies named VIP-3, VIP-3H, and VIP-4H are described in the following. These processes use a single polycrystalline silicon layer architecture for the base-emitter formation. VIP-3 and VIP-3H use junction isolation, whereas VIP-4H uses a dielectrically isolated process with trenches and BESOI wafers.

\section{A. VIP-3}

A high performance and low cost complementary bipolar technology has been developed for the realization of high-precision and high-frequency analog circuits [29]. The technology, referred to as VIP-3, offers transistors with typical $B V_{\text {ceo }}$ for NPN and PNP transistors of 45 and $60 \mathrm{~V}$, respectively, with other device specifications detailed in Table I. The technology uses deep junction isolation, a deep n-well for the PNP vertical isolation, twin buried layers, n-type epitaxial layer, combined with single-poly quasiself-aligned emitter/base transistor 
TABLE I

List OF DEVICE PARAMETERS FOR THE VIP-3, 3H, AND 4H TeChNOLOGY. $A_{e}=4 \times 20 \mu \mathrm{m}^{2}$

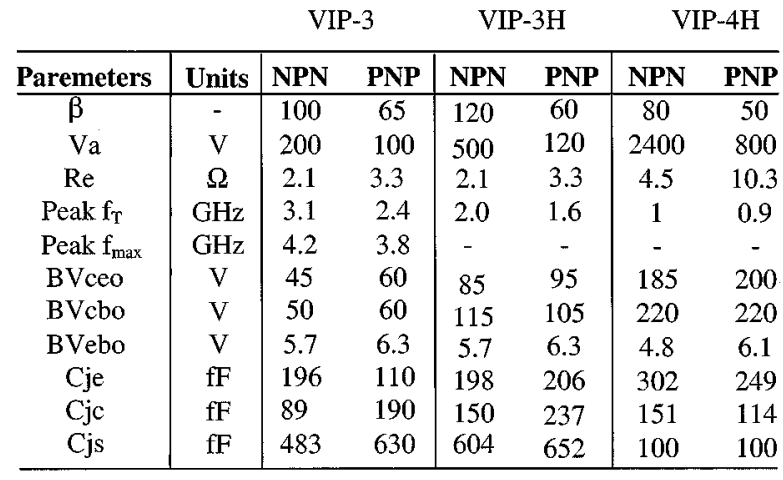

structure with a minimum feature size of $2 \mu \mathrm{m}$. The process also offers $\mathrm{n}$ and p-type polycrystalline silicon resistors and polycrystalline silicon/oxide/metal capacitors. A cross-section view of the NPN and PNP devices is depicted in Fig. 2.

Process Flow: Fig. 3 shows the module process flow for the complementary bipolar process. The process begins on a p-type substrate into which phosphorus is implanted and driven to form the deep n-well for the PNP vertical isolation. Next, the n-type antimony buried layer for the NPN is implanted and driven. Since the collector resistance and hence the saturation voltage ( $\left.V_{\text {cesat }}\right)$ needs to be minimized, heavily doped "sinker" regions need to be formed to access the buried layer from the top of the wafer. The epitaxial layer thicknesses are large for these voltage ranges and hence, only a sinker-down dopant region is not sufficient to connect to the buried layer. Thus, the n-type phosphorus sinker-up is formed by ion implantation. Next, boron implant is used to form the PNP buried layer regions and the isolation areas. A rapid thermal anneal cycle is performed prior to epitaxial growth to eliminate implant damage in the n-type sinker-up and PNP buried layer regions. Epitaxial deposition is performed in a reduced pressure, radiantly heated barrel reactor at $1080{ }^{\circ} \mathrm{C}$. An n-type, $8.5 \mu \mathrm{m}$-thick epitaxial layer is grown.

Next, n-type and p-type sinker-down regions and p-well dopants are implanted in the epitaxial layer through a pad oxide. The formation of vertical PNP transistors, along with vertical NPN transistors, is a complex task due to the added requirement of the formation of the P well. In the VIP-3 process, an n-type epitaxial layer was grown and counter doped to form the $\mathrm{P}$ well of the PNP transistors. The counter doping requires a p-type dopant which needs to diffuse down to merge with the boron buried layer. Aluminum is a p-type dopant in silicon and has a diffusion coefficient that is about an order of magnitude higher than that of boron [41]-[44]. Boron implants were also used for the formation of the shallow region of the $\mathrm{P}$ well. Next, a nitride layer is deposited and defined for a standard LOCOS process. A diffusion/oxidation cycle is used to link the n-type sinker-up and n-type sinker-down regions and to link the PNP buried layer and p-type sinker-down regions.

After the sinker diffusion/LOCOS formation, intrinsic and extrinsic bases are implanted through a pad oxide into the silicon using photoresist masks. Windows through the pad oxide are opened and a polycrystalline silicon layer is deposited. The
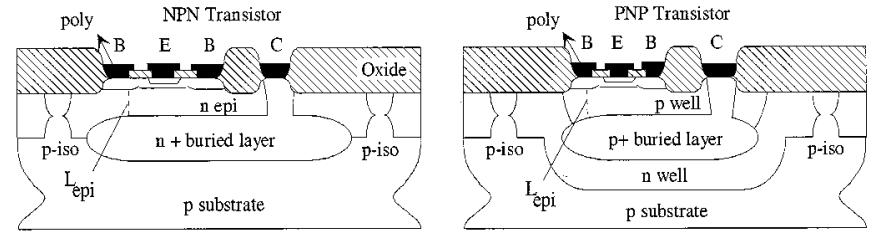

Fig. 2. Cross-sectional diagram of the VIP-3 and VIP-3H NPN and PNP transistor.

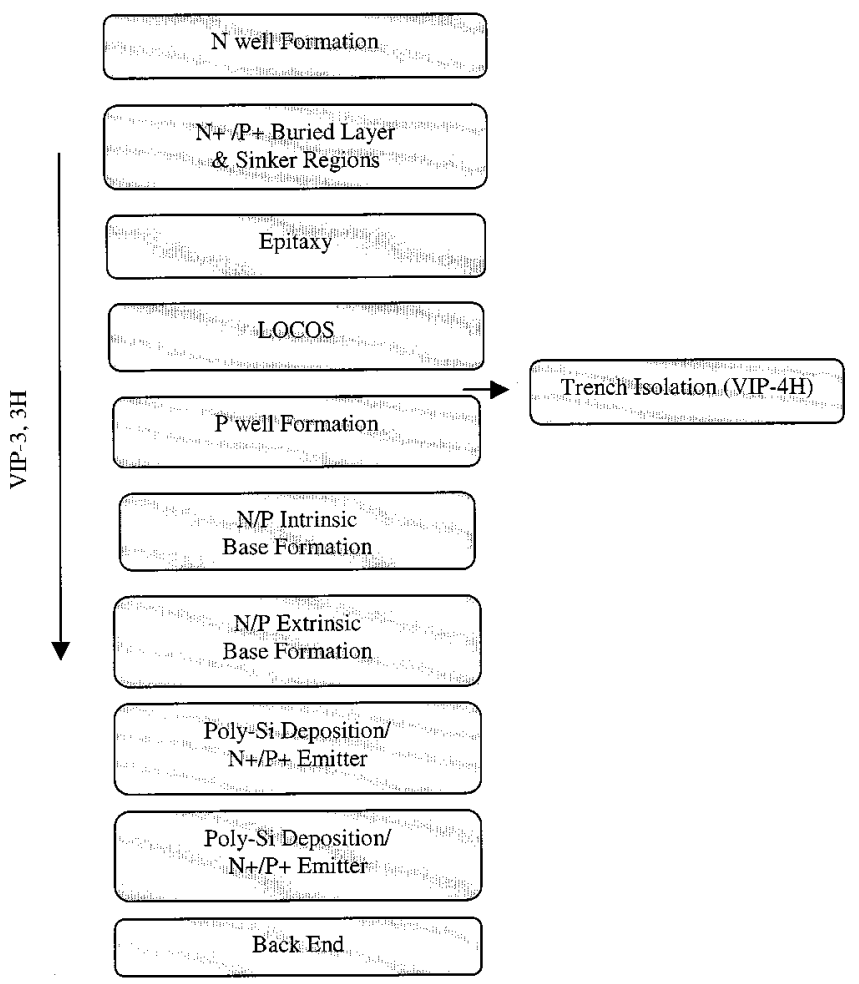

Fig. 3. Modular process flow for the VIP complementary bipolar technology.

wafer clean process prior to the polycrystalline silicon deposition consists of pirahana $\left(1: 1 \mathrm{H}_{2} \mathrm{O}_{2}: \mathrm{H}_{2} \mathrm{SO}_{4}\right)$ clean followed by a short exposure in 10:1 hydrofluoric acid. The wafers are then loaded in the CVD tube at $400{ }^{\circ} \mathrm{C}$ and the tube is pumped down to reduce oxidation prior to deposition. The temperature is then ramped to the final polycrystalline silicon deposition temperature. This scheme has been shown to provide consistent and repeatable electrical results, thus enhancing manufacturability of polyemitter bipolar process [39]. Following the polycrystalline silicon deposition, an RTA step is used to break any interfacial native oxide. The polycrystalline silicon layer is then implanted with boron and arsenic for the emitter regions. Furnace anneal cycles are finally used to diffuse the dopant from polycrystalline silicon into the monocrystalline silicon regions to form and activate the emitter and extrinsic base contact regions.

Electrical Results: Fig. 4 shows the $I_{c}-V_{c e}$ characteristics of the VIP-3 NPN transistor, while Fig. 5 shows the $I_{c}-V_{c e}$ characteristics of the PNP transistor. Fig. 6 shows the Gummel plot of both NPN and PNP transistors exhibiting constant gain over seven decades indicating excellent material and junction quality. The current gain $(\beta)$, early voltage $\left(V_{a}\right)$, collectoremitter breakdown voltage $\left(B V_{\text {ceo }}\right)$, and junction capacitance for the NPN/PNP devices are listed in Table I. The higher PNP 


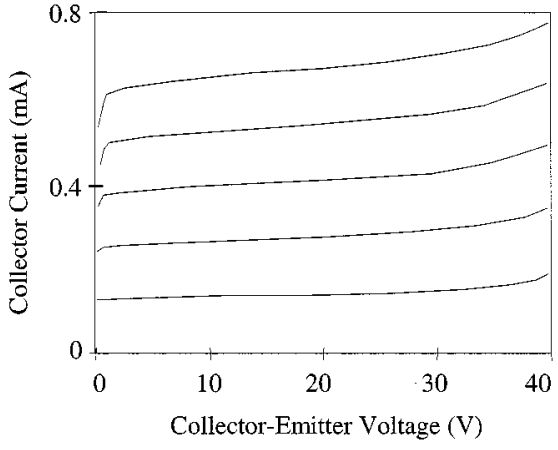

Fig. 4. $I_{c}$ versus $V_{c e}$ for a VIP-3 NPN device with area of $2 \times 20 \mu \mathrm{m}^{2}$; Ib steps of $1 \mu \mathrm{A}$.

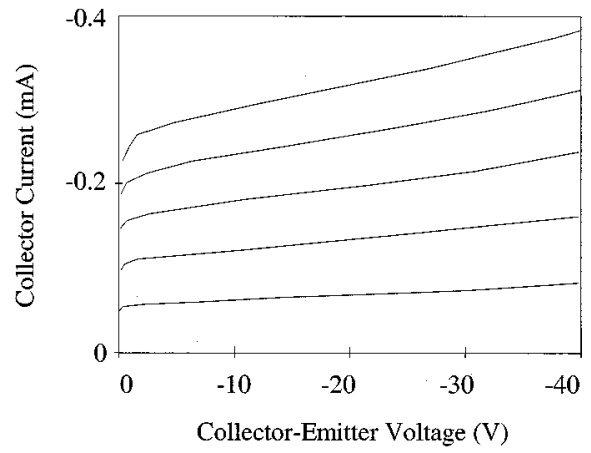

Fig. 5. $I_{c}$ versus $V_{c e}$ for a VIP-3 PNP device with area of $2 \times 20 \mu \mathrm{m}^{2} ; I b$ steps of $1.5 \mu \mathrm{A}$.

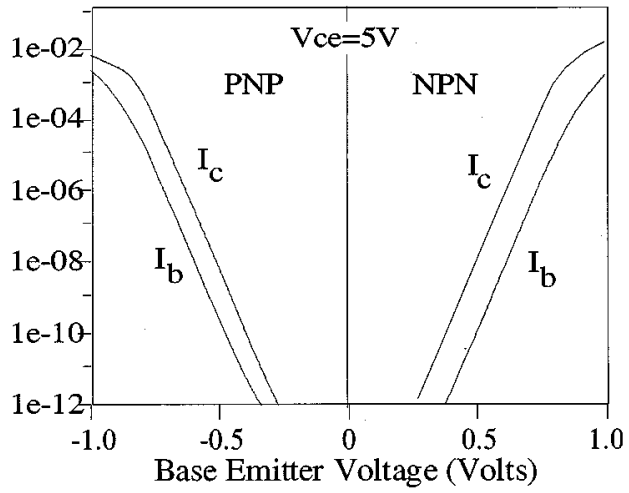

Fig. 6. Gummel plots for the VIP-3 NPN and PNP devices, area $=2 \times$ $20 \mu \mathrm{m}^{2}$.

$B V_{\text {ceo }}$ is attributed to the reduced susceptibility to avalanche breakdown [30]. It is to be noted that unlike many complementary processes, VIP- 3 process offers PNP $f_{T}$ being $77 \%$ to that of the NPN $f_{T}$, attributed mainly to p-well process design and optimization. The maximum oscillation frequency, $f_{\max }$, is obtained from the unilateral gain measurement. Note that the $f_{\max }$ values are in the $\mathrm{GHz}$ range even for $4 \times 20 \mu \mathrm{m}^{2}$ emitter and the values for the PNP are $90 \%$ of those of the NPN transistor.

\section{B. $V I P-3 H$}

A high-performance and low-cost complementary bipolar technology has also been developed for the realization of highprecision, high-frequency, and high-voltage analog circuits for the monitor and CRT market. The process also achieves its high performance without the use of expensive modules such as trench isolation or bonded wafers.

Process Flow: The process flow is very similar to the VIP-3 process flow described previously, except that higher breakdown voltages are obtained by increasing the epitaxial layer thickness and increasing the resistivity. The final cross-section view of the NPN and PNP devices is very similar to the one depicted in Author inconsistent with math variables. Fig. 2.

To form the deep portion of the p-well, boron, and aluminum implantation and diffusion were used rather than $\mathrm{MeV}$ Boron implantation. The epitaxial layer thickness was increased to $13.5 \mu \mathrm{m}$ and hence the thick n-type epitaxial layer has to be compensated to form the p-well for the PNP device. The key issues with aluminum are its very high diffusivity (an order of magnitude higher than boron) and low electrical activity, i.e., approximately, only $1 / 40$ of the implanted dose becomes activated following the well drive [43], [44].

Electrical Results: The Gummel plots of the VIP-3H devices exhibited a constant gain over seven decades of current, indicating excellent material quality for both devices just as for the VIP-3 devices. The collector-substrate breakdown voltage was optimized using process and device simulators. The NPNburied layer to p-type substrate breakdown is determined by the avalanche breakdown at the junction at the edge of the buried layer since that is where the field gradient is the highest and can be controlled by substrate doping. The PNP buried layer to p-type substrate breakdown requires a careful selection of the n-well doping to optimize the trade-off between the punchthrough voltage in the n-well and avalanche breakdown at the periphery. If the n-well doping is low, then breakdown occurs due to punch-through of the $n$-well under the $\mathrm{p}+$ buried layer. If the n-well doping is high, then avalanche breakdown occurs at the periphery.

The $B V_{\text {ceo }}$ and $B V_{\text {ceo }}$ were the other key breakdown values to be increased to greater than $85 \mathrm{~V}$. Since $B V_{\text {ceo }}$ is limited by $B V_{\text {cbo }}$ according to $B V_{\text {cbo }} \cong B V_{\text {ceo }} \beta^{1 / m}, B V_{\text {cbo }}$ was optimized first. The $B V_{\text {cbo }}$ is limited by the edge breakdown effects. A deeper extrinsic base results in a smaller junction curvature at the edges and hence, a higher breakdown. On the other hand, if the distance from the extrinsic base-collector junction to the buried layer is too small then $B V_{\text {cbo }}$ will be limited by the reach-through of the depletion region to the buried layer. This collector-base depletion region reach-through sets the thickness of epitaxial layer.

$B V_{\text {ceo }}$ is a function of the intrinsic or "planar" $B V_{\text {cbo }}$ provided that the intrinsic $B V_{\text {cbo }}$ breakdown is higher than the terminal $B V_{\text {cbo }}$ limited by edge effects. This is the case for VIP-3H where due to the thicker epitaxial layer under the intrinsic base, the intrinsic $B V_{\text {cbo }}$ is much higher than the terminal $B V_{\text {cbo. The }}$ intrinsic $B V_{\text {cbo }}$ could not be measured but was obtained using simulations as shown in Fig. 7. Also shown in Fig. 7 is the measured $B V_{\text {cbo }}$ and $B V_{\text {ceo }}$ for the NPN and PNP with the final optimized doping profiles. It should be noted that due to the up-diffusion of boron-buried layer, the distance $L_{e p i}$ for PNP is half than that for NPN. The $B V_{\text {cbo }}$ for PNP is still high and this is attributed to the smaller impact ionization rate for holes as compared to electrons [40]. 


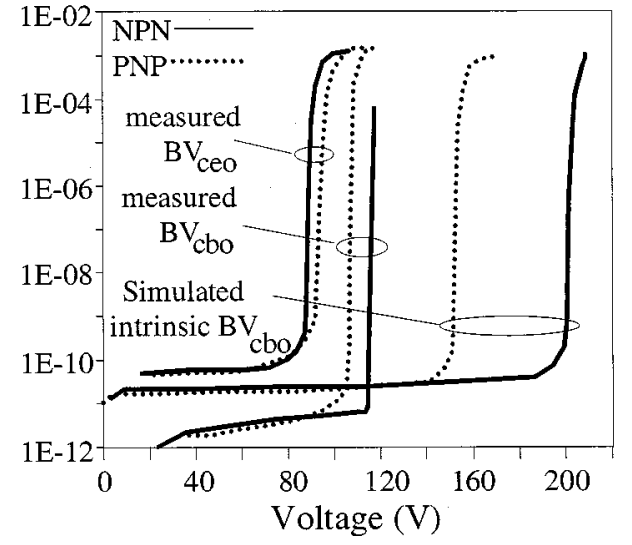

Fig. 7. VIP-3H NPN and PNP collector-base and collector-emitter breakdown voltages.

\section{VIP-4H}

VIP-4H is a high-speed complementary bipolar IC process for applications requiring up to $170 \mathrm{~V}$ collector to emitter breakdown from both NPN and PNP transistors. Examples of such applications are subscriber line interface circuits for telephone central offices, CRT driver applications, and high voltage audio amplifiers [45]-[48]. For such high voltage bipolar ICs, which necessarily have thick epitaxial layers, the dielectric isolation scheme used in VIP-4H has a large die size advantage over traditional junction isolation. An additional benefit is the elimination of all parasitic substrate devices, which improves latchup immunity and radiation hardness.

Process Architecture: The starting materials is $2.5 \mu \mathrm{m}$ of $\langle 100\rangle$ - oriented SOI over a $1 \mu \mathrm{m}$ buried oxide fabricated using a BESOI process obtained from commercial vendors. After implantation and annealing of $\mathrm{n}+$ (antimony) and $\mathrm{p}+$ (boron) buried layer, and an n-type (phosphorus) "sinker-up" (which goes in NPN collector contact regions, as well as forming the buried layer of low-voltage NPN transistors), a thick $(>20$ $\mu \mathrm{m})$ high-resistivity n-type epitaxial layer is grown. P-well, $\mathrm{n}$-sinker, and $\mathrm{p}$-sinker regions are then defined and implanted through a screen oxide. Active and field areas are defined by a standard nonrecessed LOCOS oxidation. Incorporated into the field oxidation cycle is a high-temperature anneal for the sinkers and p-well. Plasma-enchaned tetraethylorthosilicate (TEOS) source was used as a trench hard-mask for the deep trench etching in a magnetically enhanced RIE system using $\mathrm{HBr}: \mathrm{NF}_{3}: \mathrm{He}-\mathrm{O}_{2}$ chemistry. An isotropic etch and sacrificial oxidation were used to remove any damages created on the trench sidewall. After growth of a trench liner oxide, the trench was filled with polycrystalline silicon which was etched back and then oxidized to cap the trench surface.

The remaining process is similar to the VIP-3H process and formed the device extrinsic base and emitter regions. A cross sectional view of a complete deep trench isolated device is depicted in Fig. 8.

Electrical Results: Typical high-voltage transistor characteristics are also summarized in Table I. Output characteristics of mesh-emitter NPN and PNP transistors with approximately $1000 \mu \mathrm{m}^{2}$ emitter area are shown in Figs. 9 and 10. Note that the Early voltage $V_{a}$ is very dependent on collector current. Most of

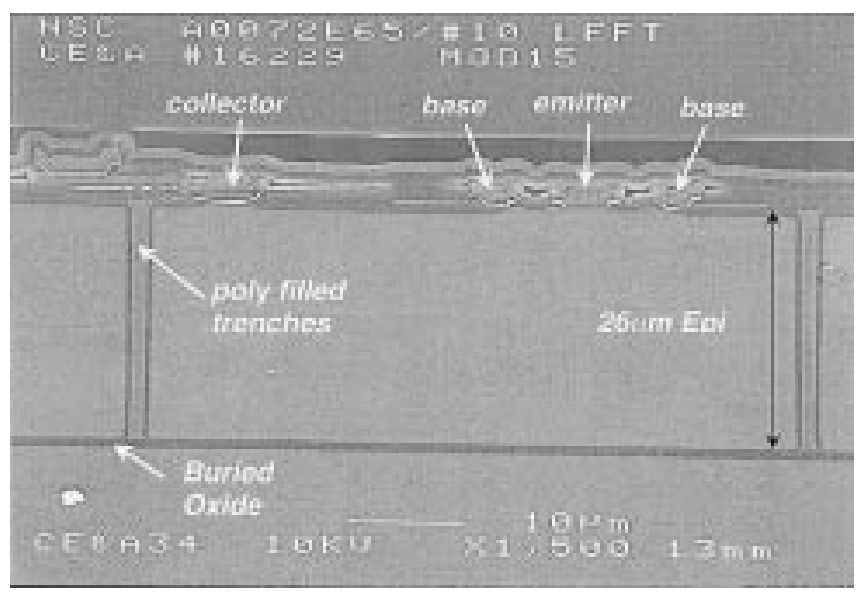

Fig. 8. Cross-sectional SEM of a VIP-4H transistor.

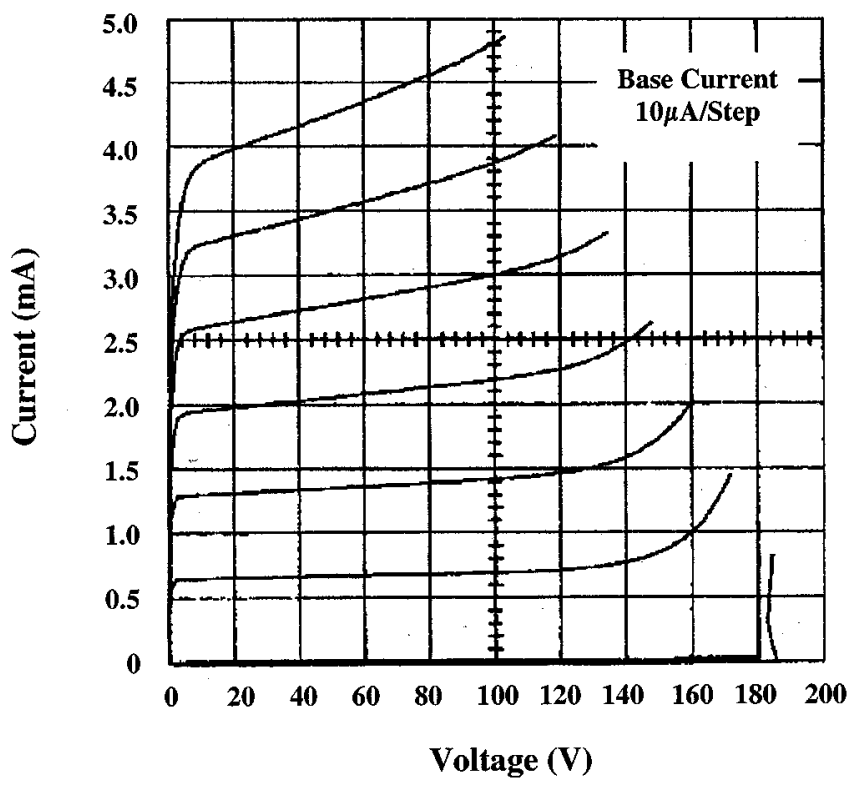

Fig. 9. $I_{c}$ versus $V_{c e}$ for a VIP-4H NPN devices.

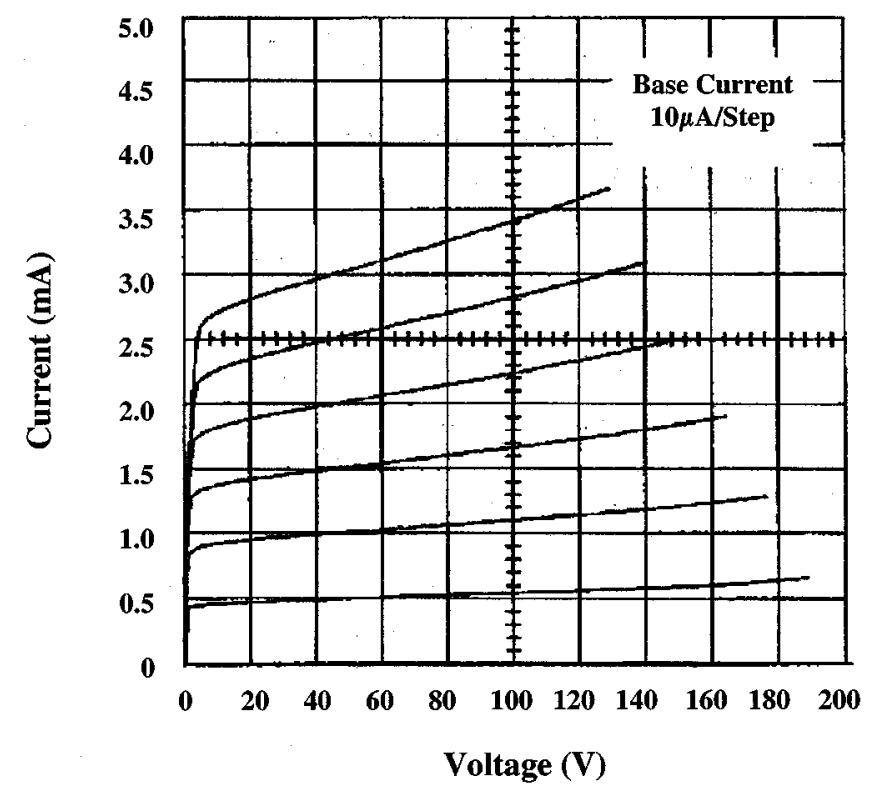

Fig. 10. $I_{c}$ versus $V_{c e}$ for VIP-4H PNP devices. 
TABLE II

$\beta$ AND $V a$ FOR NPN/PNP DEVICES WITH AND WITHOUT GROWN INTERFACIAL OXIDE

\begin{tabular}{c||c|c||c|c}
\multicolumn{1}{c}{} & \multicolumn{2}{c}{ NPN } & \multicolumn{2}{c}{ PNP } \\
& $\beta$ & $V_{\mathrm{a}}$ & $\beta$ & $\mathrm{V}_{\mathrm{a}}$ \\
\hline Wafer A & 105 & 200 & 50 & 75 \\
\hline Wafer B & 400 & 482 & 82 & 326 \\
\hline
\end{tabular}

the observed increase in output conductance at high $I_{C}$ is a result of self-heating [49], as the thermal conductivity of silicon dioxide is about a factor of 100 lower than that of silicon. The Early voltages given in Table I are measured at low current and voltage levels where self-heating effects are not significant. The isolation breakdown between adjacent trenches, as measured by a serpentine isolation test structures with $4.32 \mathrm{~mm}$ in length, was found to be $530 \mathrm{~V}$ with very low leakage.

\section{POLYCRYSTALLINE SiLicon EMITTER AND INTERFACE CHARACTERIZATION}

The current transport of the BJT, and the $\beta$ and early voltage are a strong function of the monosilicon/polycrystalline silicon interface properties. The current gain is a ratio of the carriers injected from the emitter to base and the carriers backinjected from the base to the emitter. In the presence of an interfacial oxide, the tunneling-limited back injection of carriers decreases and the current gain increases. The theory for the transport has been investigated by many groups extensively [50], [51]. An experiment was performed to examine the effect of an interfacial oxide on NPN and PNP devices on the same wafer and is described below [52].

Experiments and Results: After device isolation formation in the VIP process, intrinsic bases were implanted in the device regions. HF-last clean was used on two sets of wafers. Wafer set A was loaded at $400{ }^{\circ} \mathrm{C}$ in the deposition tube and polycrystalline silicon was deposited at $625{ }^{\circ} \mathrm{C}$ as per the standard process. Wafer set $\mathrm{B}$ was loaded at $625{ }^{\circ} \mathrm{C}$ in air, heated at $625{ }^{\circ} \mathrm{C}$ for $20 \mathrm{~min}$, and then polycrystalline silicon was deposited at $625{ }^{\circ} \mathrm{C}$. Wafers were then rapid thermal annealed at $1060{ }^{\circ} \mathrm{C}$ for $20 \mathrm{~s}$, and the standard process was continued. High-resolution TEM of the NPN and PNP emitter regions in wafer set A showed no interfacial oxide. In fact, epitaxial regrowth of the polycrystalline silicon emitter to the silicon substrate was observed as expected. High-resolution TEM in the PNP device of wafer set B showed a $22 \AA$ oxide, while the NPN exhibited a $14 \AA$ Axide. Table II shows the key electrical parameters of the wafer A and B. Figs. 11 and 12 show the SRP of the NPN and PNP devices without (wafer A-standard process) and with interfacial oxide (wafer B). It is clear that an oxide is present which prevents diffusion of emitter dopant in both types of devices in wafer B. The reduction in emitter diffusion due to the interfacial oxide results in a higher base peak doping and a higher base dose which increases the early voltage. Even though the effective base doping concentration is higher, the current gain is also significantly higher, which is due to the reduction

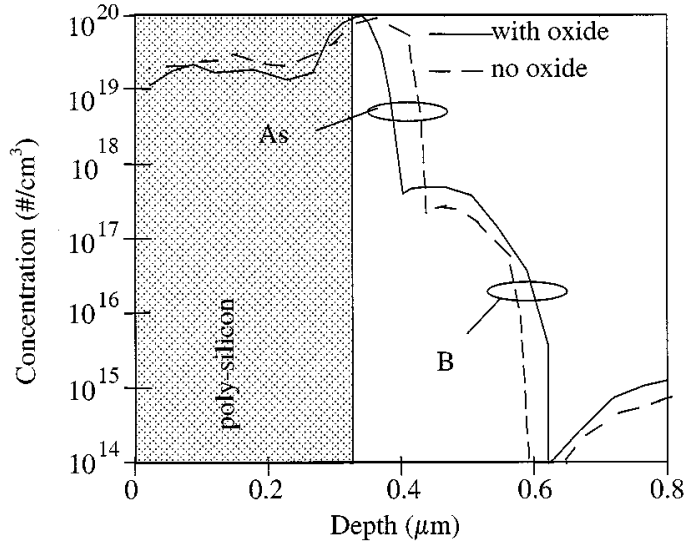

Fig. 11. SRP of the NPN with and without the grown interfacial oxide.

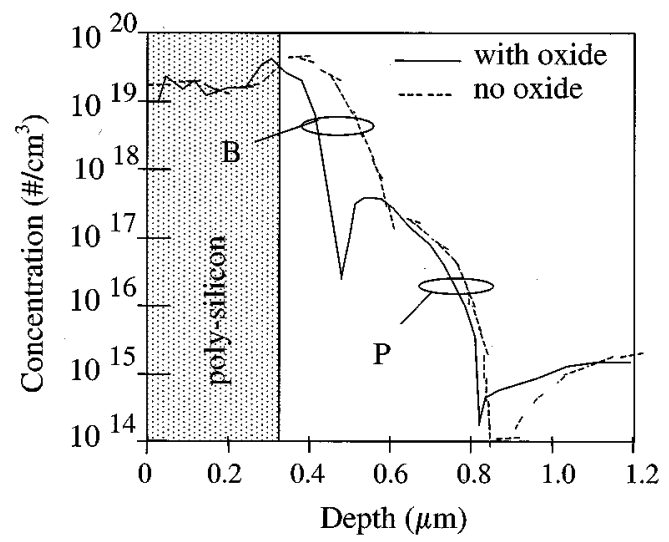

Fig. 12. SRP of the PNP with and without the grown interfacial oxide.

in the backinjected current. The enhancement in the PNP current gain of wafer B is less than the enhancement in the NPN current gain, as shown in Table II, due to two main reasons. Firstly, the probability for the back injected electrons is high and the barrier height is low, even though the interfacial oxide is thicker in the PNP. This does not increase the emitter injection efficiency as much. Secondly, the emitter is deeper for the PNP, which could cause increased recombination resulting in reduced enhancement. It should also be noted that the emitter resistance, not discussed in this paper, would also be increased due to the presence of the interfacial oxide. Earlier study extracted the probabilities of the backinjected electrons and holes and found the electron probability to be about $5 \times$ that of the hole back injection probability [52].

\section{TRENCH ISOLATION AND CHARACTERIZATION}

For high voltage devices, the lateral and vertical isolation of the devices from each other consumes significant space due to the distances required by depletion regions from adjacent devices. Deep trench isolation combined with BEBSOI wafers produces significant reduction in device size and the corresponding die size for high voltage processes when compared to junction isolation. In addition, the buried oxide layer provides additional reduction in space for vertical PNP devices since no $\mathrm{N}$ well diffusion is needed for the vertical PNP isolation. The field oxide isolation in high voltage devices is usually based on 


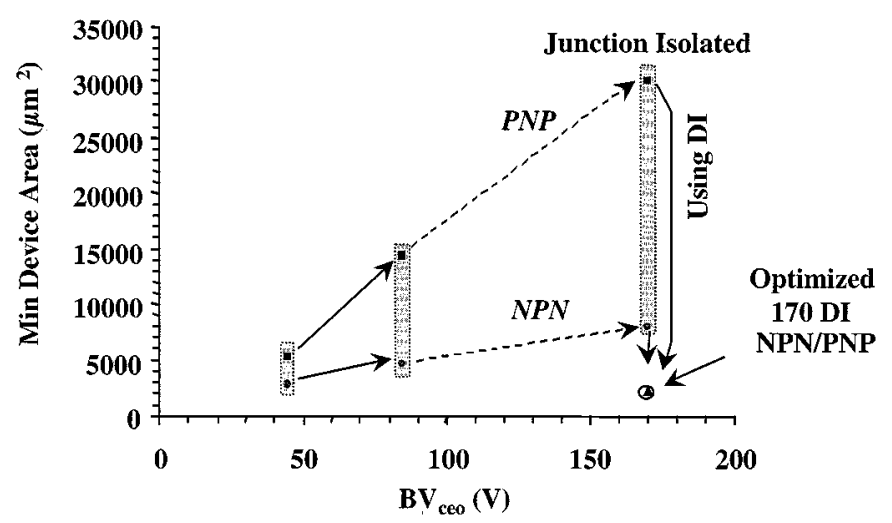

Fig. 13. Transistor size of minimum emitter $(2 \mu \mathrm{m} \times 4 \mu \mathrm{m})$ from the VIP-3, VIP-3H, and VIP-4H technologies. Note the dramatic reduction in device size of the dielectrically isolated VIP-4H transistors when compared to its junction isolated counterpart.

LOCOS (or a derivative thereof) since replacement of the field oxide with a shallow trench isolation scheme will not provide a significant reduction in device size. Fig. 13 shows the total device size (including isolation) for the transistors from the three VIP technologies. For junction isolation (JI) technologies, the NPN device size is usually smaller than the PNP due to the additional area taken up by the $\mathrm{N}$ well isolation and its contact. However, it should be noted that when dielectric isolation (DI) is used, the device areas is reduced significantly.

For the VIP-4H process, a magnetically enhanced reactive ion etch system (MERIE) was used to define the deep trenches utilizing an $\mathrm{HBr} / \mathrm{NF}_{3} / \mathrm{He}-\mathrm{O}_{2}$ plasma chemistry [31], [35], [36], [55], [56]. The primary benefit of an azimuthally rotating magnetic field parallel to the wafer surface is enhancement of ionization rate by induction of electrons into helical trajectories between collisions allowing lower pressure operation without loss of etch rate [57]. Polycrystalline silicon is an ideal fill material since the mean free path is very long at typical low-pressure deposition conditions and can fill very high aspect ratio trenches. Oxide, on the other hand, can only be used to fill shallower trenches (less than $10 \mu \mathrm{m}$ ) and even then the fill shows voids when filled with thermal decomposition of TEOS at atmospheric pressure [31]. Subatmospheric pressure TEOS oxide has the potential to fill deep silicon trenches for reduced sidewall parasitic capacitance. Fig. 14 shows a TEM of the optimized and planarized deep trench isolation process used in the VIP-4H technology.

\section{CiRCUIT EXAMPles}

A high-performance PNP in the signal path offers the opportunity for designing push-pull circuits for analog applications. In addition, a vertical PNP makes a truly precision band gap reference (where parasitic bipolar devices fail). The VIP technologies have been used to realize many voltage and current feedback amplifier circuits. A high-speed, low-power voltage-feedback operational amplifier was designed and demonstrated [58]. The low current version of this chip has a bias current of $2.5 \mathrm{~mA}$ at $\pm 15 \mathrm{~V}$ supply and a bandwidth of $110 \mathrm{MHz}$. The slew rate was $2000 \mathrm{~V} / \mu \mathrm{s}$. Another version of the circuit exhibited a bias current of $6.5 \mathrm{~mA}$ at the same supply voltage and a bandwidth of $200 \mathrm{MHz}$ [59]. These circuits were also shrunk to produce

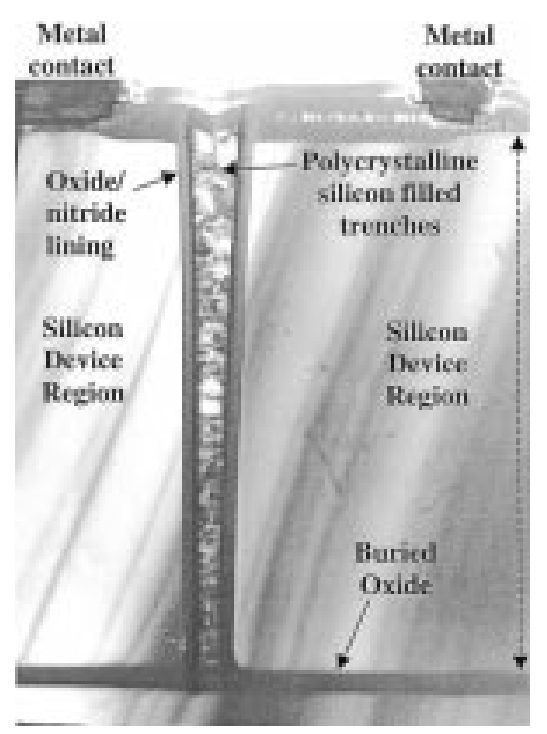

Fig. 14. Cross-sectional TEM of the deep trench isolation structure isolating two adjacent thick SOI device regions in the VIP-4H process.

a high-speed, voltage-feedback operational amplifier capable of operating from $\pm 1.8 \mathrm{~V}$ to $\pm 20 \mathrm{~V}$ supplies and driving infinite capacitive load. Silicon evaluations showed $188 \mathrm{MHz}$ bandwidth and $1500 \mathrm{~V} / \mu$ s slew rate. The die size was $38 \times 46 \mathrm{mil}^{2}$ in a tiny SOT package [60].

Another application of the high voltage process is in the cathode ray tube (CRT) which requires high-voltage and highspeed drivers (in excess of $40 \mathrm{MHz}$ ). Usually, discrete components are used to realize CRT Display drivers due to the lack of high-frequency and high-voltage monolithic approaches. A cascode output driver stage is used to allow for output voltage swings in excess of the $B V_{\text {ceo }}$ (but not $B V_{\text {ces }}$ ) of the devices. In the VIP-3H technology, a family of monolithic CRT Drivers has been designed which is capable of achieving a $40 \mathrm{~V} \mathrm{p}-\mathrm{p}$ swing in less than $9.5 \mathrm{~ns}$ into $12 \mathrm{pF}$ loads [62]. The use of vertically integrated high voltage PNP transistors not only simplifies circuit design, but improves performance. The output stage is an example of a high power, high frequency stage that is difficult to implement in a process with only high frequency NPN transistors. The close performance characteristics of the two device polarities allow high speed symmetrical drive to the CRT cathode.

\section{CONCLUSIONS}

Complementary bipolar technologies are a cornerstone of analog circuits such as voltage and current feedback amplifiers, high-precision current mirrors, and push-pull circuits. This paper presented a detailed background and description of silicon complementary bipolar process technologies. Specifically, a family of processes called VIPTM was described with technology versions at 40,85 , and $170 \mathrm{~V}$ device breakdowns. The 40 and $85 \mathrm{~V}$ processes were junction isolated but the $170 \mathrm{~V}$ process was dielectrically isolated with deep trenches and SOI wafers. Key process issues such as the polycrystalline silicon emitter optimization and trench isolation were discussed. Circuit examples were provided to demonstrate the viability and usefulness of the technologies. 


\section{ACKNOWLEDGMENT}

The authors would like to thank the 5" (in CA) and 6" (in TX) fabrication facility and management at National Semiconductor Corporation for the support of this work.

\section{REFERENCES}

[1] D. W. Oberlin, "Complementary bipolar transistors for monolithic structures," in IEDM Tech. Dig., 1968, p. 20.

[2] B. Polata, "Compatible, high performance complementary bipolar transistors for integrated circuits," in IEDM Tech. Dig., 1969, p. 82.

[3] S. C. Su and J. D. Meindl, "A new complementary bipolar structure," IEEE J. Solid-State Circuits, vol. SC-7, pp. 351-357, Oct. 1972.

[4] R. M. McLouski, "Fabrication considerations for complementary bipolar circuits," J. Electrochem. Soc., vol. 120, p. 90C, Mar. 1973.

[5] J. D. Beasom, "A triple diffused process for the simultaneous fabrication of NPN, PNP, and MOS devices in isolated P and N type regions," U.S. Patent 3865649,1975

[6] C. G. Jambotkar, "High performance complementary bipolar transistor," IBM Tech. Disclosure Bull., vol. 20, pp. 1396-1399, Sept. 1977.

[7] N. G. Anantha and H. S. Bhatia, "Complementary bipolar transistor process for enhancing PNP transistor performance," IBM Tech. Discl. Bull., vol. 21, pp. 4845-4847, May 1979.

[8] N. G. Anantha, H. S. Bhatia, D. B. Eardley, and G. R. Srinivasan, "Isolated complementary bipolar transistors on same chip with enhanced NPN performance," IBM Tech. Discl. Bull., vol. 21, p. 4867, May 1979.

[9] V. Y. Doo, "Nine-mask complementary bipolar process," IBM Tech. Discl. Bull., vol. 22, pp. 1874-1878, Oct. 1979.

[10] D. W. Aull, D. A. Spires, P. C. Davis, and S. F. Moyer, "A high-voltage IC for a transformerless trunk and subscriber line interface," IEEE J. Solid-State Circuits, vol. SC-16, no. 4, pp. 261-266, Aug. 1981.

[11] P. J. Meza, D. P. Laude, R. C. Strawbrich, and R. M. Sirisi, "A two chip subscriber line interface circuits with ringing," in Proc. 1983 IEEE Int. Solid-State Circuits Conf.. Piscataway, NJ: IEEE, 1983.

[12] T. Sakurai, T. Ohno, K. Kato, Y. Inabe, and T. Hayashi, "A dielectrically isolated complementary bipolar technique for analog/digital compatible LSIs," IEEE Trans. Electron Devices, vol. ED-30, pp. 1278-1283, Oct. 1983.

[13] H. Sadamatsu, M. Inoue, A. Matsuzawa, A. Kanda, and H. Shimoda, "New self-aligned complementary bipolar transistors using selective oxidation mask," in IEDM Tech. Dig., 1984, pp. 753-756.

[14] M. Inoue, A. Matsuzawa, A. Kanda, and H. Sadamatsu, "Self aligned complementary bipolar transistors fabricated with a selective oxidation mask," IEEE Trans. Electron Devices, vol. ED-34, pp. 2146-2152, Oct. 1987.

[15] A. Feygenson, J. W. Osenbach, W. L. Buchanan, and J. J. Bastek, "CBIC-V a new very high speed complementary bipolar analog process on SOI," in Proc. 1989 BCTM, Minneapolis, MN, pp. 173-177.

[16] T. Maeda, K. Ishimaru, and H. Momose, "Lower submicron FCBiMOS (fully complementary BiMOS) process with RTP and MeV implanted $5 \mathrm{GHz}$ vertical PNP transistor," in Proc. Symp. VLSI Technology. Piscataway, NJ: IEEE, 1990, pp. 79-80.

[17] S. Goacher, "Excalibur technology," Electron. Eng., vol. 62, p. 4, Oct. 1990.

[18] C. Davis, G. Bajor, J. Butler, T. Crandell, J. Delgado, T. Jung, Y. KhajehNoori, B. Lomenick, V. Milam, H. Nicolay, S. Richmond, and T. Rivoli, "UHF-1: A high speed complementary bipolar analog process on SOI," in Proc. 1992 BIPOLAR/BiCMOS Circuits and Technology Meeting, Minneapolis, MN, 1992, pp. 260-263.

[19] S. Feindt, J. Hajjar, J. Lapham, and D. Buss, "XFCB: A high speed complementary bipolar process on bonded SOI," in Proc. 1992 BIPOLAR/BiCMOS Circuits and Technology Meeting, Minneapolis, MN, 1992, pp. 264-267.

[20] S. Feindt, J. Lapham, and J. Steigerwald, "Complementary bipolar processes on bonded SOI," in IEEE Int. SOI Conf., Yosemite, CA, 1997, pp. 4-6.

[21] S. Feindt, J. Lapham, J. Steigerwald, Y. Nakazato, and M. Katayama, "Bonded SOI application to high performance linear devices," in Proc. 4th Int. Symp. Semiconductor Wafer Bonding: Science, Technology, and Applications Paris, France, 1998.

[22] T. Yamaguchi, T. Archer, R. Johnston, and J. Lee, "Process and device optimization of an analog complementary bipolar IC technology with 5.5-GHz $\mathrm{f}_{\mathrm{T}}$ PNP transistors," IEEE Trans. Electron Devices, vol. 41, pp. 1019-1026, June 1994.
[23] T. Archer, T. Yamaguchi, R. Johnston, and J. Lee, "Process optimization for a complementary bipolar IC technology with 5.5-GHz f $\mathrm{T}_{\mathrm{T}}$ PNP transistors," in Proc. 1993 Bipolar BiCMOS Circ. Technology, Minneapolis, MN, 1993, pp. 128-131.

[24] J. D. Cressler, J. Warnock, D. L. Harame, J. N. Burghartz, J. Joachim, K. Jenkins, and C. Chuang, "High-speed complementary silicon bipolar technology with 12-fJ power-delay product," IEEE Electron Device Lett., vol. 14, pp. 523-526, Nov. 1993 .

[25] C. T. Chuang, J. D. Cressler, and J. D. Warnock, "AC-coupled complementary push-pull ECL circuit with $34 \mathrm{fJ}$ power-delay product," Electron. Lett., vol. 29, no. 22, pp. 1938-1939, 1993.

[26] R. Jerome, I. R. C. Post, P. G. Travnicek, G. M. Wodek, K. E. Huffstater, and D. R. Williams, "Acute: A high performance analog complementary polysilicon emitter bipolar technology utilizing SOI/trench full dielectric isolation," in IEEE Int. SOI Conf., Palm Springs, CA, 1993, pp. 100-101.

[27] R. Jerome, I. Post, K. Huffstater, G. Wodek, P. Travnicek, and D. Williams, "Effect of trench processing conditions on complementary bipolar analog devices with SOI/trench isolation," in Proc. 1993 Bipolar/Bicoms Circuits and Technology Proc., Minneapolis, MN, 1993, pp. 41-44.

[28] A. H. Pawlikiewicz, A. Bishop, and R. Jerome, "Low noise and high tolerance to radiation effects of complementary bipolar SOI IC technology," in Proc. IEEE NSREC'95, Madison, NJ, 1995, pp. 78-84.

[29] R. Bashir, J. DeSantis, D. Chen, F. Hebert, A. Ramde, P. Maghsoudnia, H. You, P. Meng, F. Moraveji, and R. Razouk, "A 40 volt silicon complementary bipolar technology for high-precision and high-frequency analog circuits," in Proc. IEEE Bipolar/BiCMOS Circuits and Technology Meeting, Minneapolis, MN, 1994, pp. 225-228.

[30] R. Bashir, D. Chen, F. Hebert, J. DeSantis, A. Ramde, S. Hobrecht, H. You, P. Maghsoudnia, P. Meng, and R. Razouk, "A 85 volt high performance silicon complementary bipolar technology for high voltage analog applications," in Proc. 24th Eur. Solid State Device Research Conf. Edinburgh, U.K., 1994, pp. 217-220.

[31] K. C. Brown, C. Bracken, R. Bashir, K. Egan, J. DeSantis, A. E. Kabir, W. Yindeepol, J. McGregor, S. J. Prasad, R. Razouk, V. Boksha, and J. C. Rey, "Trench isolation technology for high-performance complementary bipolar devices," Proc. SPIE, vol. 2875, pp. 48-61, 1996.

[32] T. Onai, E. Ohue, Y. Idei, M. Tanabe, H. Shimamoto, and W. Hiromi, "NPN/PNP $30 \mathrm{GHz}, 32 \mathrm{GHz} \mathrm{f}_{\mathrm{T}}$ complementary bipolar technology," in Proc. Int. Electron Devices Meeting. Piscataway, NJ: IEEE, 1993, pp. 63-66.

[33] — - "Self-aligned complementary bipolar technology for low-power dissipation and ultra-high speed LSI's," IEEE Trans. Electron Devices, vol. 42, pp. 413-418, Mar. 1995.

[34] H. Miwa, H. Ammo, H. Ejiri, S. Kanematsu, and T. Gomi, "Complementary bipolar technology for low cost and high performance mixed analog/digital applications," in Proc. IEEE Bipolar/BiCMOS Circuits and Technology Meeting, Minneapolis, MN, 1996, pp. 185-188.

[35] J. M. McGregor, W. Yindeepol, J. DeSantis, K. Brown, R. Bashir, and W. McKeown, "170 Volt polysilicon-emitter complementary bipolar IC technology with full dielectric isolations," in Proc. IEEE Bipolar/BiCMOS Circuits and Technology Meeting, Minneapolis, MN, 1997, pp. 183-186.

[36] Yindeepol, R. Bashir, J. M. McGregor, K. Brown, I. De Wolf, J. De Santis, and A. Ahmed, "Defect free deep trench isolation for high voltage bipolar application on SOI wafer," in IEEE Int. SOI Conf., Stuart, FL, 1998, pp. 151-152.

[37] R. Patel, W. Milam, G. Cooley, M. Corsi, J. Erdeljac, and L. Hutter, "30 V complementary bipolar technology on SOI for high speed precision analog circuits," in Proc. IEEE Bipolar/BiCMOS Circuits and Technology Meeting, Minneapolis, MN, 1997, pp. 48-50.

[38] M. C. Wilson, P. H. Osborne, S. Nigrin, S. B. Goody, J. Green, S. J. Harrington, T. Cook, S. Thomas, A. J. Manson, and A. Madni, "Process HJ: A $30 \mathrm{GHz}$ NPN and $20 \mathrm{GHz}$ PNP complementary bipolar process for high linearity RF circuits," in Proc. IEEE Bipolar/BiCMOS Circuits and Technology Meeting, Minneapolis, MN, 1998, pp. 164-167.

[39] N. S. Parekh, R. V. Taylor, and D. O. Massetti, "Simple method to control bipolar polysilicon emitter interfacial oxide," J. Electrochem. Soc., vol. 141, pp. 3167-3172, Nov. 1994.

[40] J. Warnock, P. F. Lu, T. C. Chen, K. Y. Toh, J. D. Cressler, K. A. Jenkins, D. D. Tang, J. Burghartz, J. Y. C. Sun, C. T. Chuang, G. P. Li, and T. H. Ning, "A 27 GHz 20 ps PNP Technology," in Proc. 1989 Int. Electron Devices Meeting, Washington, DC, Dec. 3-6, 1989, pp. 903-905.

[41] A. Scandurra, G. Galvagno, V. Raineri, F. Frisina, and A. Torrisi, "Diffusion and electrical behavior of Al implanted into capped Si," J. Electrochem. Soc., vol. 140, no. 7, pp. 2057-2062, 1993. 
[42] G. Galvagno, A. Scandurra, V. Raineri, C. Spinella, A. Torrisi, A. La Ferla, V. Sciascia, and E. Rimini, "Al-based precipitate evolution during high temperature annealing of Al implanted in Si," J. Electrochem. Soc., vol. 140 , no. 8 , pp. $2313-2318,1993$.

[43] G. Galvagno, F. La Via, F. Priolo, and E. Rimini, "Diffusion and outdiffusion of aluminum implanted into silicon," Semicond. Sci. Technol. vol. 8, pp. 488-494, 1993.

[44] G. Galvagno, F. La Via, M. G. Saggio, A. La Mantia, and E. Rimini, "Twodimensional aluminum diffusion in silicon: Experimental results and simulations," J. Electrochem. Soc., vol. 142, no. 5, pp. 1585-1590, 1995.

[45] B. Zoher, R. Koban, R. Petschacher, and W. Sereinig, "A 150V subscriber line interface circuit (SLIC) in a new BiCMOS/DMOS technology," in BCTM, 1996, pp. 93-96.

[46] D. W. Aull, D. A. Spires, P. C. Davis, and S. F. Moyer, "A high-voltage IC for a transformerless trunk and subscriber line interface," IEEE J. Solid-State Circuits, vol. SC-16, pp. 261-266, Aug. 1981.

[47] M. Metcalf, "A $175 \mathrm{MHz}$ video display driver IC," in BCTM, 1986, pp. 65-66.

[48] I. Imaizumi, "Novel IC structure for 150V high-voltage consumer IC," IEEE Trans. Consumer Electron., vol. EC-26, pp. 367-375, Aug. 1980

[49] P. Ganci, J. Hajjar, P. Humphries, J. Lapham, and D. Buss, "Self-heating in high performance bipolar transistors fabricated in SOI substrates," in Proc. IEDM, San Francisco, CA, 1992, pp. 417-420.

[50] H. C. de Graaff HC and J. G. de Groot, "The SIS tunnel emitter: A theory for emitters with thin interface layers," IEEE Trans. Electron Devices, vol. ED-26, pp. 1771-1776, Nov. 1979.

[51] K. Suzuki, "Unified minority-carrier transport equation for polysilicon or heteromaterial emitter contact bipolar transistors," IEEE Trans. Electron Devices, vol. 38, pp. 1868-1877, Aug. 1991.

[52] R. Bashir, F. Hebert, D. Basile, and D. Su, "Investigation of hole and electron back injected tunneling currents in a poly-silicon emitter complementary bipolar technology," in ESSDERC'96, Proc. 26th Eur. SolidState Device Research Conf. Bologna, Italy, 1996, pp. 219-224.

[53] K. K. Ng and H. C. Card, "Asymmetry in the $\mathrm{SiO}_{2}$ tunneling barriers to electrons and holes," J. Appl. Phys., vol. 51, pp. 2153-2157, Apr. 1980.

[54] M. E. McNie, D. O. King, V. Nayar, M. C. Ward, J. S. Burgess, C. Quinn, and S. Blackstone, "Deep dry etching of SOI for silicon micromachined structures," in Proc. 1997 IEEE Int. SOI Conf., Yosemite, CA, pp. 60-61.

[55] R. Bashir, F. Wang, W. Yindepool, J. DeSantis, and J. McGregor, "Back gated buried oxide MOSFET's in a high voltage bipolar technology for bonded oxide/SOI interface characterization," IEEE Electron Device Lett., vol. 19, p. 282, Aug. 1998.

[56] R. Bashir and F. Hebert, "PLATOP: A novel planarized trench isolation and field oxide formation using poly-silicon," IEEE Electron Device Lett., vol. 17, pp. 352-354, July 1996.

[57] M. Engelhardt, "Optimized high rate deep silicon trench etching for dielectric isolation in smart power devices," in ECS Ext. Abstr., 1994,p. 336.

[58] F. Moraveji, "A low-power, high-speed, voltage-feedback operationa amplifier on a low-cost 40 volt complementary bipolar technology," in Proc. 1994 Bipolar/BiCMOS Circuits and Technology Meeting, Minneapolis, MN, 1994, pp. 19-22.

[59] J. Bales, "Low-power, high-speed, current-feedback op-amp with a novel class AB high current output stage IEEE," J. Solid-State Circuits, vol. 32, pp. 1470-1474, Sep. 1997.

[60] F. Moraveji and M. Musbah, "A tiny, high-speed, voltage-feedback amplifier stable with all capacitive loads," in Proc. 1995 Bipolar/BiCMOS Circuits and Technology Meeting, Minneapolis, MN, 1995, pp. 23-26.

[61] F. Moraveji, "Wide-band, low-power, high slew rate voltage-feedback operational amplifier," IEEE J. Solid-State Circuits, vol. 31, pp. 10-16, Jan. 1996.

[62] T. Mills and F. Hebert, "A triple-channel $90 \mathrm{~V}$ high-speed monolithic CRT driver circuit," in Proc. 1995 Bipolar/BiCMOS Circuits and Technology Meeting, Minneapolis, MN, 1995, pp. 66-69.

Rashid Bashir (M'95) received the B.S.E.E. degree from Texas Tech University, Lubbock, as the highest ranking graduate in the College of Engineering, in 1987. He received the M.S.E.E. and Ph.D. degrees from Purdue University, West Lafayette, IN, in 1989 and 1992, respectively.

From October 1992 to October 1998, he was with the Analog/Mixed Signal Process Technology Development Group, National Semiconductor, Santa Clara, CA. He was promoted to Senior Engineering Manager, Process Technology Group. He worked on developing state-of-the-art bipolar, complementary bipolar, and BiCMOS process for high voltage, analog and RF applications, SiGe HBT devices, SOI bonded wafers for high voltage device isolation, and MEMS technologies. He is currently an Associate Professor of Electrical and Computer Engineering with Purdue University. He has authored or co-authored over 50 journal and conference papers and over 20 patents.
François Hébert was born in Manitoba, Canada, in 1961. He received the B.A.Sc, M.A.Sc, and Ph.D. degrees in electrical engineering from the University of Waterloo, Waterloo, ON, Canada, in 1984, 1985, and 1988, respectively.

From 1988 to 1993, he developed radio frequency (RF)/microwave bipolar and integrated circuits at Avantek Corporation (now part of Agilent), Newark, CA. From 1993 to 1995, he was Senior Engineering Manager at National Semiconductor, Santa Clara, CA, involved in the development of high-performance analog technologies, including the VIP-3 and VIP-3H complementary bipolar technologies and other bipolar/CMOS/DMOS technologies. From 1995 to 1999 , he was Director of Semiconductor Technology, Spectrian Corporation (now UltraRF), Sunnyvale, CA, where he managed the development of RF-Bipolar and RF-LDMOS discrete products for high-power base station applications in the $900 \mathrm{MHz}$ to $2.5 \mathrm{GHz}$. Since June 1999, he has been at Linear Technology Corporation, Milpitas, CA, where he is involved in the development of high-performance BiCMOS technologies for analog and mixed-signal applications. He has more than 30 granted U.S. patents and has published over 25 journal publications and conference proceedings. His current interests include integration of high-voltage structures, complementary technologies, RF technologies for wireless applications including RF-LDMOS and SiGe, and device/process simulations.

Dr. Hebert is a member of the IEEE Electron Devices Society

Joseph DeSantis received the B.S. degree in microelectronics from the Rochester Institute of Technology, Rochester, NY, in 1990.

He has been with National Semiconductor, Santa Clara, CA, since 1991 as a Process Engineer. His projects have included complementary bipolar processes (VIP-3,VIP3H, and VIP-4H), high-speed epitaxial base processes using silicon and silicon germanium, and CMOS process development. He has also worked in the photo and etch unit process development.

Joel M. McGregor, photograph and biography not available at the time of publication.

Wipawan Yindeepol received the M.S. degree in electrical engineering from Oregon State University, Corvallis, in 1991.

She has been an Integration Engineer with National Semiconductor, Santa Clara, CA, since 1991. She has been engaged in developing bipolar, BiCMOS ( $\mathrm{SiGe}$ ), and CMOS processes. She is currently working on high-speed complementary bipolar technology development. She has five publications and five U.S. patents in her name.

Kevin Brown received the B.S. degree from Carnegie Mellon University, Pittsburgh, PA, and the M.S. degree from the University of Southern California, Los Angeles, both in materials science.

$\mathrm{He}$ is currently with Micrel Semiconductor, San Jose, CA, after eleven years at National Semiconductor, Santa Clara, CA, working in the areas of thins films, plasma etch, and analog process technology. He has over ten papers published and five patents in the field of semiconductor processing.

Farhood Moraveji received the B.S. degree in electrical engineering from the University of Shiraz, Iran, in 1979, and the M.S. degree in electrical engineering from Santa Clara University, Santa Clara, CA, in 1987.

From 1979 to 1983, he was with Pars Toshiba Company designing circuits for TV and VTR. He joined the Linear Design Group at National Semiconductor Corporation, Santa Clara, CA, in 1987, where worked on sensors and high-speed, high-precision analog circuits. Currently he is with Micrel Semiconductor, San Jose, CA. He has published several papers in the IEEE journals and holds seven U.S. patents. His area of interest is high-speed analog and RF circuit design. 
Thomas B. Mills was born in California in 1937 and received with the B.S.E.E. degree from the University of Arizona, Tucson, in 1960.

From 1960 to 1962, he worked on spacecraft electronics at Philco Western Development Labs, Palo Alto, CA. From 1962 to 1970, he was with Fairchild Semiconductor doing applications for consumer semiconductors and integrated circuit design. He joined National Semiconductor, Santa Clara, CA, in 1970 as Design Manager for consumer linear integrated circuits. At National Semiconductor, he has held a variety of design and applications positions in the consumer electronics area and is presently engaged in the design of high-speed, high-voltage circuits. He has published numerous papers on semiconductor applications and holds three patents.

Alexei Sadovnikov was born in Ufa, USSR, in 1955. He received the M.S. and Ph.D. degrees in microelectronics from the Moscow Institute of Physics and Technology (MIPhT), Moscow, USSR, in 1978 and 1983.

From 1983 to 1991, he was an Assistant Professor with MIPhT, and from 1992 to 1996, he was a Research Scientist with the University of Waterloo, Waterloo, ON, Canada. During these years, he developed numerical methods and physical models for commercial processes and device simulators. In 1996, he joined the Advanced Process Development Group, National Semiconductor, Santa Clara, CA, and was involved in TCAD simulation support of numerous projects: 0.25-0.18 um CMOS, 0.65-0.5um smart power, and high-voltage complimentary BJTs. He published more than 30 technical papers and a book TCAD of High-Speed Bipolar ICs. His current research interests include application of process/device simulators for advanced process development in industrial environment.

James McGinty (M'96) received the B.Sc. degree in electrical and electronic engineering from Paisley University, Paisley, U.K., in 1988, and the M.Sc. degree in VLSI design from Bournemouth University, Bournemouth, U.K., in 1990.

In 1991, he joined National Semiconductor, Greenock, U.K. From 1991 to 1995, he was with the Device Physics Group, working on CMOS, DMOS, and BIPOLAR technologies. In 1996, he joined the Analog Process Technology Development Group, where he worked on advanced high-speed BIPOLAR technology development, and is now the TCAD Team Leader. His research interest activities are focused on process simulation, high-speed devices, statistical TCAD, and high-voltage device simulation. He has published 12 papers in the area of statistical TCAD and process simulation.
Peter Hopper, photograph and biography not available at the time of publication.

Robert Sabsowitz, photograph and biography not available at the time of publication.

Mohamed Khidr was born in Egypt. He received the B.S. degree in physics and the Ph.D. degree from the University of Budapest, Budapest, Hungary, in 1960 and 1968, respectively.

He was with Fairchild Semiconductor from 1968 to 1972. From 1972 to 1977, he was with Burrows Corporation and Signetics/Philips Electronics from 1977 to 1991. He joined National Semiconductor, Santa Clara, CA, in 1991, and has held leading engineering positions in development and manufacturing of analog, mixed signal, and digital technologies.

Tracey Krakowski received the B.S degree in physics from the State University of New York at Fredonia and the B.S. degree in electrical engineering from Rochester Institute of Technology, Rochester, NY, in 1992.

In 1993, she joined the Analog Process Development Group, National Semiconductor, Santa Clara, CA, where she worked in the Device Modeling Group. Currently, she manages the parameter extraction for power BiCMOS and $\mathrm{HF} / \mathrm{HV}$ complementary bipolar technologies.

Linda Smith received the B.S. degree in physics from the University of California, Santa Cruz, and the M.S. degree in electrical engineering from the University of Santa Clara, Santa Clara, CA.

She is currently the Director of SPICE Model Parameters, National Semiconductor, Santa Clara, CA, where she is responsible for SPICE models for CMOS, BiCMOS, and Bipolar technologies.

Reda Razouk, photograph and biography not available at the time of publication. 